\title{
Cuidados de la piel y las uñas del anciano
}

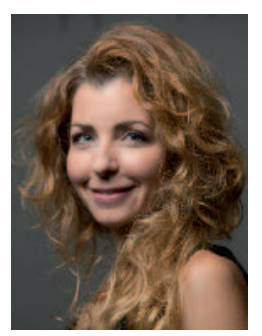

Elena González-Guerra Médico adjunto del Servicio de Dermatología. Hospital Clínico San Carlos. Madrid.

Profesora asociada de Dermatología. Universidad Complutense de Madrid.

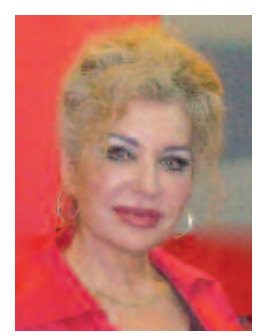

Aurora Guerra Tapia Jefa de Sección de Dermatología. Hospital Universitario 12 de Octubre. Madrid. Profesora titular de Dermatología. Universidad Complutense de Madrid.

\section{RESUMEN}

Un anciano es una persona de mucha edad que puede identificarse a simple vista por el estado de su piel y su cabello. En la piel del anciano, se producen, entre otros, una serie de cambios epidérmicos —en los queratinocitos, las células de Langerhans y los melanocitos- que favorecen la piel seca, las infecciones y las alteraciones tanto de la inmunidad como de la pigmentación. En la dermis, disminuye la función de los fibroblastos, lo que lleva a la mengua del soporte cutáneo y, por lo tanto, propicia las arrugas. La higiene con jabones de $\mathrm{pH}$ ácido $(5,5)$ y aditivos grasos (syndets), la hidratación tópica con principios activos seleccionados y la fotoprotección farmacológica representada por los filtros solares son la base del cuidado de la piel del anciano. A estos pilares se puede añadir un tratamiento correctivo de las arrugas y manchas con cosméticos y cosmecéuticos reparadores. Las uñas requieren un cuidado especial por su frecuente infección por hongos.

Palabras clave: anciano, piel sana, uñas, cuidados.

\section{ABSTRACT}

An elderly man or woman is an old aged person, who can be identified at first sight by the state of his/her skin and hair. In the skin of the elderly are, amongst others, a series of changes-epidermal keratinocytes, Langerhans cells and melanocitos favoring dry skin, infections, and impaired immunity and pigmentation. In the dermis, the fibroblast function decreases, leading to the decline of cutaneous support and, therefore, promoting wrinks. Hygiene with acid $\mathrm{pH}$ (5.5) and fatty additives (syndets) soap, topical moisturizing with selected active ingredients and pharmacological photoprotection represented by sunscreens are the basis of skin care in the elderly. To these pillars a corrective treatment of wrinkles and blemishes can be added with cosmetics and cosmeceuticals repairers. Nails require special care because of their frequent fungal infection.

Keywords: elderly, healthy skin, nails, care. 
Y dijo la esfinge: se mueve a cuatro patas por la mañana, camina erguido al mediodía, y utiliza tres pies al atardecer.

¿Qué cosa es?

Y Edipo respondió: el hombre. Las tres edades.

\section{ANCIANO}

La definición de 'anciano' del Diccionario de la lengua española de la Real Academia Española reza así: «Dicho de una persona: de mucha edad».

El Diccionario de términos médicos de la Real Academia Nacional de Medicina añade que no existe un límite preciso para separar la edad madura de la vejez, aunque se suele establecer de forma arbitraria en los 65 años. Aun aceptando estos enunciados, es muy difícil unificar criterios a este respecto, dada la frecuente discordancia existente entre la edad cronológica y la edad biológica de un individuo. A menudo, dos personas que nacieron en el mismo año muestran importantes diferencias en su aspecto externo.

De lo que no hay duda es de que el concepto de anciano desde un punto de vista físico puede determinarse a simple vista por el estado de su piel y su cabello ${ }^{1}$.

Así lo demuestran varias obras pictóricas que podríamos titular genéricamente Las tres edades del hombre, como la de Giorgio Barbarelli da Castelfranco, apodado el Giorgione (1477-1510), la de Hans Baldung (1484-1545), la de Tiziano Vecellio (1490?-1576) o la de Gustav Klimt (1862-1918), por poner algunos ejemplos (fig. 1).

La población mundial, y de forma fundamental la de los países industrializados, envejece progresivamente, por lo que la atención al anciano es una necesidad social cada vez más evidente? ${ }^{2}$.

\section{CAMBIOS EN LA PIEL DEL ANCIANO}

La piel es la cubierta externa de los animales superiores, que separa y protege su cuerpo del medio ambiente y facilita la percepción y comunicación con el exterior. Es el órgano más extenso del cuerpo, con una superficie aproximada de 1,6 $\mathrm{m}^{2} \mathrm{y}$

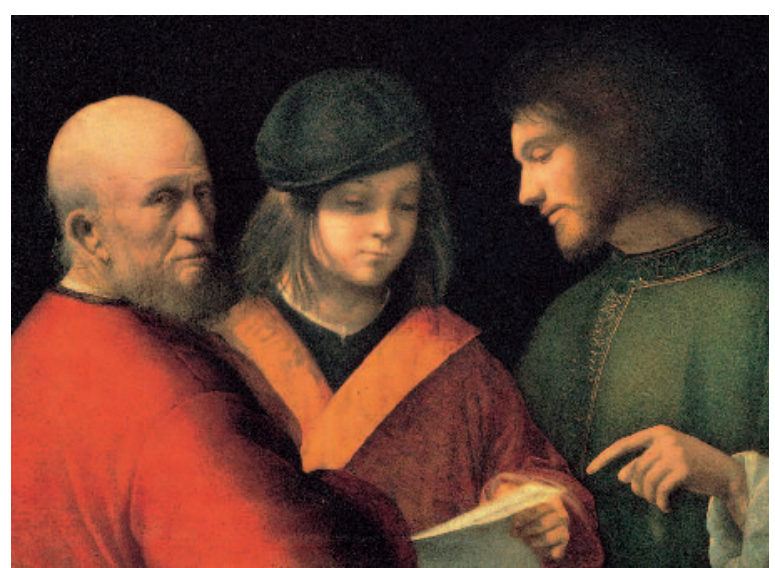

Figura 1. Las tres edades del hombre. Giorgione.

un peso de unos $4 \mathrm{~kg}$. Consta de epidermis, dermis, hipodermis o tejido subcutáneo y anejos cutáneos ${ }^{3}$.

En cada una de estas partes, se producen una serie de cambios con la edad (tabla 1), que detallaremos a continuación.

\section{Epidermis}

La epidermis es un epitelio escamoso poliestratificado queratinizado que cubre completamente la superficie corporal. Tiene un grosor de $0,4 \mathrm{a}$ 1,5 mm según las distintas zonas. Es la capa más celular y dinámica del organismo y recibe soporte y nutrición a través de la dermis, capa de tejido fibroelástico, ricamente vascularizada, en la que asienta. Está constituida, fundamentalmente, por queratinocitos y, en menor número, melanocitos, células de Langerhans y células de Merkel.

\section{Queratinocitos}

La célula fundamental epidérmica es el queratinocito, que representa el $80 \%$ de las células de 
Tabla 1. Cambios cutáneos en el envejecimiento

\begin{tabular}{|c|c|}
\hline Epidermis & $\begin{array}{l}\text { - Queratinocitos } \\
\text { - Filagrina disminuida: menor función de barrera: infecciones, xerosis } \\
\text { - Proliferación epidérmica disminuida: xerosis } \\
\text { - Células de Langerhans } \\
\text { - Menor inmunovigilancia: tumores } \\
\text { - Melanocitos } \\
\text { - Disfunción: pigmentación irregular blanca-negra } \\
\text { - Disminución: menor protección actínica }\end{array}$ \\
\hline Dermis & $\begin{array}{l}\text { - Fibroblastos } \\
\text { - Menor producción: arrugas } \\
\text { - Linfocitos T y B } \\
\text { - Mayor función: citocinas proinflamatorias } \\
\text { - Disminución del ácido hialurónico } \\
\text { - Xerosis }\end{array}$ \\
\hline Hipodermis & $\begin{array}{l}\text { - Atrofia } \\
\text { - Menor volumen }\end{array}$ \\
\hline Folículos pilosos & $\begin{array}{l}\text { - Cabello y vello: disminución } \\
\text { - Cejas: aumento } \\
\text { - Barba y bigote en mujeres: aumento }\end{array}$ \\
\hline Glándulas & $\begin{array}{l}\text { - Glándulas sudoríparas } \\
\text { - Menor producción } \\
\text { - Glándulas sebáceas en relación con andrógenos } \\
\text { - Mayor tamaño, menor función: xerosis }\end{array}$ \\
\hline Uñas & $\begin{array}{l}\text { - Lento crecimiento } \\
\text { - Engrosamiento } \\
\text { - Deformidades }\end{array}$ \\
\hline
\end{tabular}

la epidermis. Se denomina así por los filamentos de queratina que llenan su citoplasma en los estratos superficiales, agrupados en característicos haces llamados tonofilamentos.

La epidermis se regenera mediante una población de células madre queratinocíticas con gran actividad mitótica, situada en la capa basal. En los estratos epidérmicos más superficiales, los queratinocitos maduran hasta adquirir gránulos basófilos en el citoplasma llamados gránulos de queratohialina. Son precursores de la proteína filagrina, la cual provoca la agregación de los filamentos de queratina en tonofilamentos para dar lugar al siguiente estrato: la capa córnea. Las células de la capa córnea finalmente se descaman de la superficie cutánea de forma imperceptible. Este proceso de queratinización celular o renovación epidérmica tiene lugar en dos meses aproxima- damente. Las células tardan de 20 a 42 días en pasar de la capa basal a la capa granulosa, y 14 días más en convertirse en capa de queratina hasta descamarse.

Los cambios que se producen en los queratinocitos de la piel del anciano consisten en una disminución de la filagrina, lo que provoca que la capa córnea pierda eficiencia en la función de barrera y se favorezcan las infecciones y la deshidratación. Por esa causa, disminuye el factor hidratante natural, constituido por una mezcla de aminoácidos y sales procedentes de la hidrólisis de la filagrina ${ }^{4}$. Los factores ambientales influyen poderosamente en la composición del factor hidratante natural ${ }^{5}$.

También se produce una menor proliferación epidérmica o maduración corneocitaria, que lleva a la xerosis. Se estima que la xerosis o piel seca 
generalizada o difusa afecta al $75 \%$ de los individuos mayores de 75 años y que es la causa más frecuente del prurito ${ }^{6}$ originado en la piel (periférico o pruritoceptivo), conducido por fibras nerviosas de tipo C, si bien, a veces, coexiste una fisiopatología multifactorial, con componentes psicológicos tal vez sustentados por la ansiedad de la propia sequedad cutánea. La característica clínica básica de la piel seca es el aspecto áspero y descamativo con pérdida de sus propiedades mecánicas (fig. 2). Esta situación es la manifestación de que la epidermis - y, en concreto, el estrato córneo- pierde agua a una velocidad superior a la de recepción o mantenimiento de la misma, tanto transepidérmica (proveniente de la circulación sanguínea a través de la dermis) como retenida (situada entre las capas lipídicas intercorneocitarias y en su interior) ${ }^{7}$.

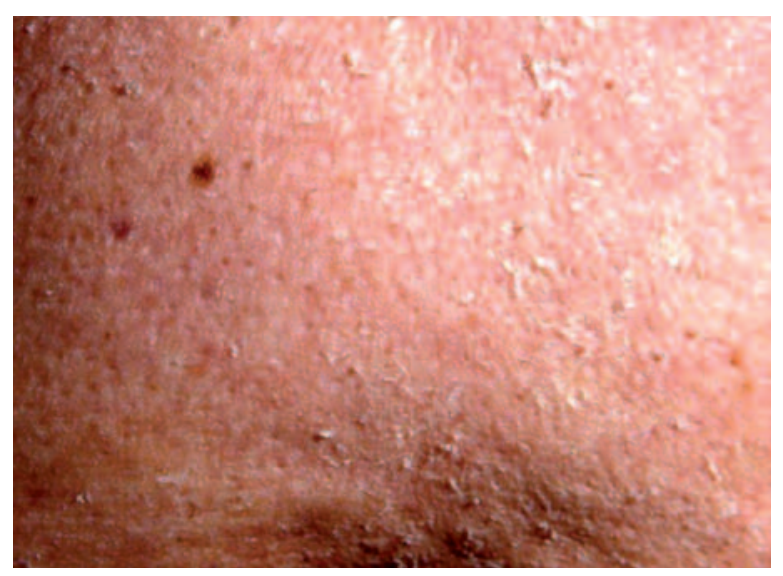

Figura 2. Xerosis o piel seca y descamativa del anciano.

Otro hecho típico de la ancianidad es la disminución de los lípidos intercelulares, que se distribuyen en bicapas entre los corneocitos. Son el sustrato sobre el que actúan las enzimas que transforman los glucoesfingolípidos en ceramidas $(50 \%)$, ácidos grasos libres esenciales y no esenciales (del 10 al $20 \%$ ) y colesterol (25\%). Las ceramidas son, a su vez, la fuente principal de ácidos grasos esenciales, entre los cuales des- taca el ácido linoleico, un elemento estructural crucial para la función de barrera epidérmica. Cuando en la piel se produce el deterioro de la síntesis de ceramidas, se ocasiona una desestructuración de la bicapa lipídica, un aumento de la pérdida insensible de agua, y una amplificación de la respuesta inflamatoria, que provoca la alteración del medio óptimo para que las enzimas epidérmicas ejerzan su labor.

Con la reducción de lípidos y de factor hidratante natural, se altera el proceso de maduración corneocitario, esto es, de la diferenciación del queratinocito, y se inhibe la necesaria y programada descamación celular. Estas modificaciones enzimáticas se convierten, así, en causa y consecuencia, cerrando el círculo vicioso que perpetúa la sequedad cutánea. Las alteraciones leves de la función de barrera suelen quedar circunscritas a la epidermis superficial, pero los daños repetidos o graves producen una respuesta inflamatoria que involucra las capas epidérmicas más profundas ${ }^{8}$.

\section{Células de Langerhans}

Son células dendríticas que se encuentran distribuidas de forma salpicada entre los queratinocitos, especialmente, en las porciones media y alta de la epidermis. Forman parte del sistema monocelular-macrofágico y se originan a partir de precursores situados en la médula ósea. Son los elementos inmunocompetentes de la piel que inducen los fenómenos proliferativos y citotóxicos de la respuesta T. Se encargan del reconocimiento y la presentación de antígenos a los linfocitos $\mathrm{T}$ y son las únicas células epidérmicas con receptores para la porción Fc de la molécula de inmunoglobulina $\mathrm{G}$ (IgG) y el complemento (C3) ${ }^{3}$.

Las variaciones que se producen en las células de Langerhans de la piel del anciano consisten en una disminución de su función inmunitaria, lo que favorece la aparición de tumores ${ }^{9}$.

\section{Melanocitos}

Son células dendríticas procedentes de la cresta neural que colonizan la epidermis durante el ter- 
cer mes de la vida fetal y permanecen como población estable en la capa basal de la epidermis. Sintetizan melanina, la almacenan y la distribuyen entre los queratinocitos vecinos a través de sus procesos dendríticos. La síntesis de melanina es un proceso metabólico complejo, catalizado por la acción de la tirosinasa, que conlleva la conversión del aminoácido tirosina, a través de intermediarios como la dihidroxifenilalanina (DOPA), en melanina. Existen dos tipos de pigmento melánico en el ser humano: la eumelanina (marrón negruzco) y la feomelanina (amarillo rojizo), que se diferencian ligeramente en su composición molecular. La función de la melanina es la protección frente a los efectos dañinos de las radiaciones ultravioleta, el control de la síntesis de la vitamina $\mathrm{D}$ y la termorregulación local.

Con la edad, va disminuyendo lentamente la población de melanocitos, con lo que, en los ancianos, la capacidad de producir melanina es menor y aumenta el riesgo de carcinogénesis actínica. Además, se produce una disfunción que lleva a una pigmentación irregular en zonas más oscuras y en zonas más claras (fig. 3).

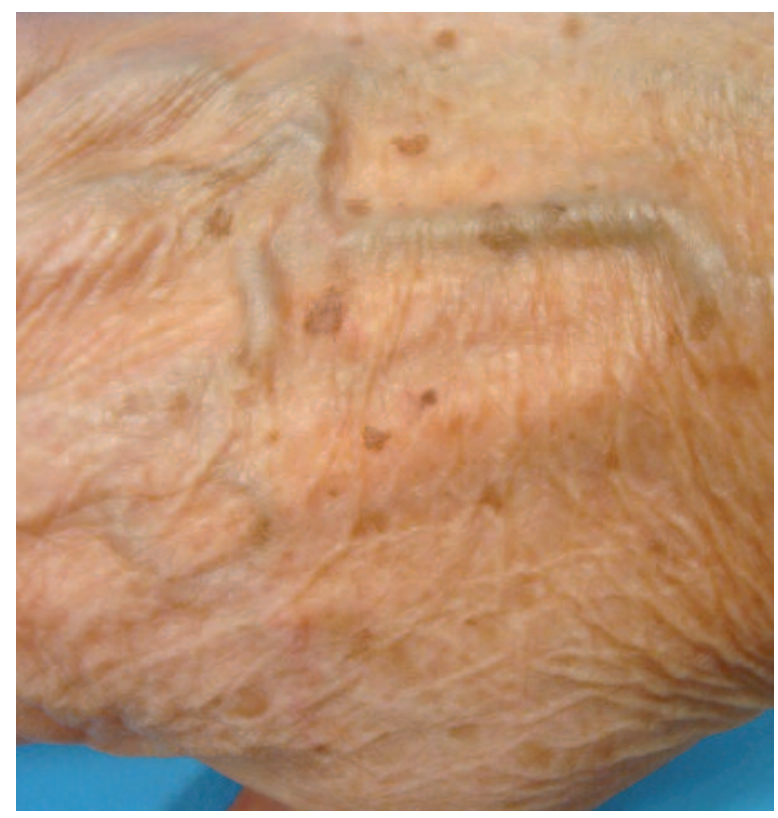

Figura 3. Alteraciones de la pigmentación.

\section{Dermis}

La dermis es la estructura de soporte de la piel. Es un tejido fibroelástico constituido por fibroblastos, fibras colágenas -especialmente, colágeno de tipo I (85-90\%), de tipo III (8-11\%) y de tipo V (2-4\%) 一, fibras elásticas y sustancia fundamental ${ }^{3}$. La red de fibras elásticas es esencial para las propiedades retráctiles de la piel, representando del 2 al $4 \%$ de los constituyentes de la dermis. Está compuesta por tres tipos de fibras - oxitalán, elaunina y elastina- dispuestas en tres capas interconectadas. En el espesor de la dermis, se encuentran los anejos cutáneos, vasos y nervios.

\section{Fibroblastos}

Constituyen la mayor parte del escaso componente celular de la dermis. Son los responsables de la síntesis de colágeno, elastina y sustancia fundamental. Los fibroblastos son células alargadas situadas entre los haces de colágeno.

En el envejecimiento, disminuye su producción y actividad, lo que favorece la aparición de las arrugas (fig. 4).

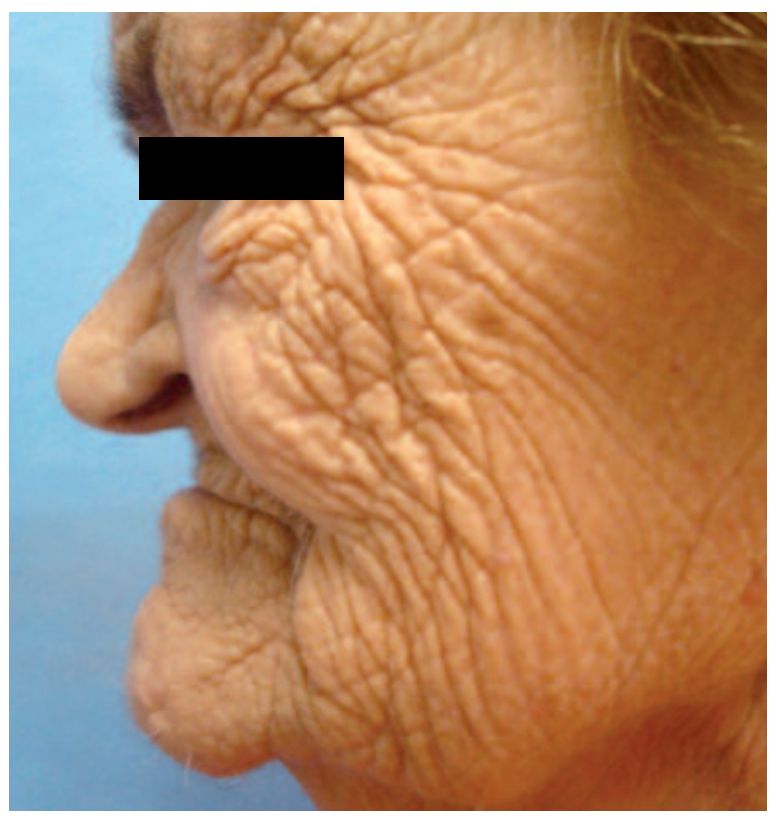

Figura 4. Arrugas en la piel de una mujer de 85 años. 


\section{Linfocitos}

Se encuentran en escaso número, siendo en un $80 \%$ linfocitos T. Se reparten de forma similar en células supresoras y cooperadoras (T8 y T4). El $20 \%$ restante son linfocitos B. Se asume que estas células linfoides tienen tareas de vigilancia inmunitaria.

En el envejecimiento, se produce una mayor función en la producción de citocinas proinflamatorias, lo que favorece los procesos inflamatorios.

\section{Sustancia fundamental}

Rellena los espacios entre fibras y células de la dermis. Está compuesta, fundamentalmente, por mucopolisacáridos, además de agua, sales y glicoproteínas. Los mucopolisacáridos mantienen el balance de sal y agua de la dermis. Son de tipo ácido no sulfatado, predominantemente, ácido hialurónico y, en menor medida, sulfato de condroitina.

Con la edad, a lo largo de la vida, disminuye el acido hialurónico, lo que favorece la deshidratación y la xerosis.

\section{Hipodermis}

El tejido subcutáneo o hipodermis está formado por lobulillos de tejido adiposo maduro, separados por tabiques conectivos finos que constituyen los septos interlobulillares; estos septos son una continuación del tejido conectivo de la dermis reticular suprayacente y, por ellos, discurren vasos y nervios. El grosor y la distribución del tejido adiposo varía enormemente en función de la edad, el sexo, la localización corporal y el estado nutricional del individuo. El tejido subcutáneo actúa como un aislante térmico y protector mecánico frente a traumatismos, además de como reservorio energético.

En el envejecimiento, la hipodermis tiende a la atrofia y disminuye su volumen, lo que favorece el descolgamiento cutáneo y las arrugas ${ }^{10}$.

\section{Anejos cutáneos}

Este término incluye los folículos pilosos, las glándulas sudoríparas, las glándulas sebáceas y las uñas.

\section{Folículo piloso}

Los pelos, constituidos por queratina dura, cubren toda la superficie corporal, excepto palmas, plantas y mucosas ${ }^{11}$. Morfológicamente, hay tres tipos de pelo (folículos pilosos): el lanugo o vello fetal, el pelo velloso fino, no pigmentado, y el pelo terminal o pelo fuerte y pigmentado. Tanto los fo lículos terminales como los vellosos tienen un ciclo de crecimiento similar, que consta de tres fases: anágena o fase de crecimiento activo del pelo, catágena o fase de involución, y telógena o fase de reposo. El crecimiento medio del cabello es de $0,3 \mathrm{~mm}$ al día y, en determinadas zonas, como son la barba, el torso, los genitales y el cuero cabelludo, está regulado por la acción de las hormonas, especialmente, los andrógenos.

En el envejecimiento, se produce una disminución del crecimiento del cabello y vello con pérdida del color o encanecimiento por disminución de la funcionalidad de los melanocitos del folículo. Sin embargo, se estimula el crecimiento de los pelos de las cejas y de los vellos de la cara en mujeres. Estos cambios están relacionados con los andrógenos.

\section{Glándulas sudoríparas ecrinas}

Las glándulas ecrinas se localizan en la piel de la mayor parte del cuerpo. Producen el sudor, compuesto, fundamentalmente, por agua. Tienen una función termorreguladora, pues la evaporación del sudor enfría la superficie corporal. El sudor contiene, además, cantidades significativas de iones de sodio, cloro, urea y otros metabolitos de bajo peso molecular, por lo que la sudoración debe considerarse un modo menor de excreción. Su regulación corre a cargo del sistema nervioso autónomo, a través de fibras colinérgicas, en respuesta a estímulos como el calor, el estrés y 
ciertos alimentos, además de los simpáticos y parasimpáticos ${ }^{3}$.

Con la edad, su producción disminuye.

\section{Glándulas sebáceas}

Las glándulas sebáceas se ubican rodeando a los folículos pilosos a un tercio de distancia de la superficie. Son glándulas multilobuladas, en las que las células germinales se sitúan en la periferia y van madurando hacia la porción central del lobulillo, acumulando lípidos en su citoplasma, que se vuelve multivacuolado, hasta que se desintegran, liberando su contenido, el sebo, dentro del conducto por un proceso conocido como secreción holocrina. Aunque existen glándulas sebáceas en todos los folículos, su tamaño y desarrollo es muy variable, siendo máximo en las denominadas zonas seborreicas, como la cara, el cuero cabelludo y la porción superior del tronco. Estas glándulas son muy pequeñas durante la infancia, pero, en la pubertad, los andrógenos estimulan su desarrollo hasta alcanzar el tamaño adulto.

En la ancianidad, disminuye su producción, lo que favorece la xerosis ${ }^{12}$.

\section{Uñas}

Son láminas queratinizadas orientadas de forma plana, rodeadas por dos surcos laterales y un surco proximal de piel altamente queratinizado, que se llama eponiquio. La piel situada por debajo del extremo libre de la uña se conoce como hiponiquio. La matriz de la uña empieza proximalmente bajo el surco ungueal proximal y, distalmente, alcanza hasta el borde de la media luna blanca o lúnula. La porción transparente de la uña está compuesta por ortoqueratina, mientras que la lúnula es opaca, porque los queratinocitos retienen su núcleo en esa porción, constituyendo paraqueratina. La proliferación continua de células en la matriz es lo que produce el crecimiento de la uña a una velocidad promedio de 0,1 mm/día (1 cm cada 100 días o unos $4 \mathrm{~mm}$ al mes en las manos, la mitad en los pies).
En la senectud, la velocidad de crecimiento de las uñas se ralentiza, siendo esta la mitad de la existente en la juventud ${ }^{13}$.

En las uñas del anciano, se observan varios cambios morfológicos, muchos de los cuales resultan dolorosos y afectan a la estabilidad y la deambulación.

Las modificaciones ungueales que aparecen de forma constante en personas de edad avanzada son, en parte, debidas a:

- La reiteración de las agresiones externas: roce, fricción, presión - en especial, en las uñas de los pies-, cambios de temperatura, exposición a diversos contactantes, etc.

- Las progresivas modificaciones fisiológicas que ocurren en el organismo, como las alteraciones vasculares, neurológicas seniles u osteoarticulares de las falanges.

- El progresivo cronoenvejecimiento de los epitelios, que se manifiesta en la lentitud de la actividad de los queratinocitos, la xerosis por disminución de los lípidos de superficie y la progresiva deshidratación.

- Los cambios hormonales y nutricionales propios de dicha época de la vida.

A todo ello, se suman las alteraciones patológicas de mayor o menor importancia, como los traumatismos, los trastornos biomecánicos, las infecciones, las enfermedades dermatológicas o sistémicas concomitantes, las medicaciones que recibe y, de forma más prevalente, la onicomicosis de las uñas de los pies -el $20 \%$ en pacientes mayores de 60 años-, que puede estar producida por hongos dermatofitos, no dermatofitos y levaduriformes. La uña del primer dedo del pie es la que se ve afectada con más frecuencia. Hay varios tipos clínicos (fig. 5): distal subungueal, proximal subungueal, blanca superficial y con paroniquia. Cuando un hongo invade la uña (extremo proximal, distal, pliegue periungueal o superficie de la lámina ungueal), produce una respuesta inflamatoria que puede originar alteraciones en su forma, consistencia y color, y se cronifica el círculo distrofia-onicomicosis-distrofia. 


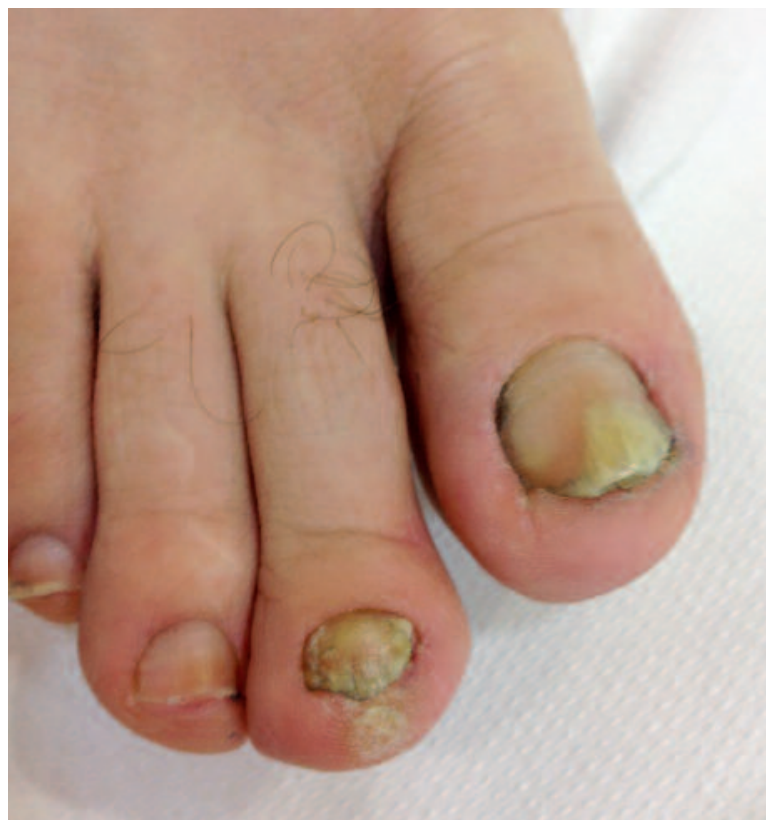

Figura 5. Uñas del anciano con onicomicosis, paroniquia y piel seca. Obsérvese la hiperqueratosis en el segundo dedo, más largo que el primero y, por lo tanto, de fácil traumatismo.

\section{CAUSAS DEL ENVEJECIMIENTO CUTÁNEO}

Aunque no se tiene absolutamente claro cuál es la causa del envejecimiento en general y de la piel en particular, existe un relativo consenso en considerar implicados los factores genéticos y hormonales, sobre los que actúan los factores ambientales. De estos últimos, los mas importantes son los ocasionados por el tabaco y la exposición a la luz solar ${ }^{1}$. La luz solar produce daño cutáneo porque las radiaciones se absorben en el ácido desoxirribonucleico $(\mathrm{ADN})$, el ácido ribonucleico (ARN), las proteínas, los orgánulos y las membranas de epidermis, dermis e hipodermis. Los efectos de las radiaciones lumínicas son acumulativos y dependientes de la dosis (fig. 3). Aunque la luz solar es necesaria para que el organismo pueda sintetizar la vitamina $\mathrm{D}$, responsable de fijar el calcio a los huesos, es suficiente la exposición de una pequeña zona cutánea (unos $10 \mathrm{~cm}$ de piel) durante 10 minutos al día dos veces por semana para cubrir las necesidades de esta vitamina.

\section{CUIDADOS DE LA PIEL SANA DEL ANCIANO}

La base de la salud de la piel, a cualquier edad y, con mayor motivo, en la ancianidad, se encuentra en una nutrición adecuada, ejercicio físico y evitar el consumo de tabaco y la fotoexposición. Junto a estas normas, se encuentran los cuidados tópicos, que exponemos a continuación.

\section{Higiene}

La higiene es el primer paso en el cuidado de la piel. Es preciso retirar la suciedad acumulada tanto por las propias secreciones como por los agentes externos con los que esta entra en contacto.

El principal agente limpiador es el jabón, que es el resultado de la reacción química (saponificación) entre un álcali (generalmente, hidróxido de sodio o de potasio) y una grasa. Puede encontrarse en forma sólida (pastilla), líquida (soluciones) o semilíquida (gel). Actúa como un surfactante de estructura micelar que atrapa la grasa, que, posteriormente, se elimina con el aclarado.

Los syndets (synthetic detergent) (jabón sin jabón) son los jabones a cuyos tensioactivos se les adicionan sustancias que atenúan su capacidad irritante. También existen cremas y emulsiones que son el resultado de la mezcla de aceite y agua con el agente tensioactivo. Por su composición grasa, son especialmente útiles en la limpieza del maquillaje.

La higiene del anciano se fundamenta en el uso de jabones con un $\mathrm{pH}$ ácido $(5,5)$ y aditivos grasos (syndets). En la cara, pueden utilizarse cremas, emulsiones o leches limpiadoras. Para retirar los restos de cremas o leches limpiadoras, se aconsejan lociones tónicas no alcohólicas. Una opción muy reconocida es la aplicación de agua termal ${ }^{10}$.

Los baños o duchas deben ser templados y de corta duración. No se debe friccionar la piel con esponjas o estropajos.

\section{Hidratación}

Es una medida fundamental que intenta suplementar o reponer todos los nichos de los que se nutre la hidratación cutánea (tabla 2). El objeti- 


\section{Tabla 2. Intervinientes en la hidratación cutánea}

\begin{tabular}{l|l}
\hline Capa córnea & - Factor hidratante natural \\
& - Aminoácidos derivados de la filagrina y la queratina \\
& - Manto hidrolipídico \\
& - Agua evaporada (perspiratio insensibilis) \\
& - Sebo \\
& - Cemento intercelular en estructura lamelar o de múltiples capas \\
& - Ácidos grasos libres (oleico, palmítico, palmitoleico, linoleico) \\
& - Ceramidas \\
& - Esteroles libres (colesterol, escualeno, ésteres de colesterol) \\
\hline Dermis & - Ácido hialurónico \\
& - Macromolécula de glicosaminoglicano capaz de captar agua hasta en un $500 \%$ \\
\hline
\end{tabular}

vo del tratamiento de la piel seca estriba en mantener un nivel óptimo de agua en la capa córnea, valiéndose de los lípidos, de las proteínas y del mantenimiento del factor hidratante natural. Hay que restituirlos mediante preparados tópicos (emolientes) diseñados específicamente para el tratamiento de la piel seca ${ }^{14}$. Se presentan en forma de leches, cremas o pomadas, es decir, emulsiones $\mathrm{O} / \mathrm{W}$ (mayor concentración de aceite - oilque de agua - water-) o W/O (mayor concentración de agua que de aceite $)^{10}$ con sustancias como las siguientes ${ }^{15,16}$.

\section{Lípidos}

Son sustitutivos de los lípidos naturales perdidos. Los agentes relipidizantes deben ser similares en composición y cantidad a los presentes en la piel de forma fisiológica (ceramidas, colesterol y ácidos grasos esenciales). Se ha descrito que los lípidos fisiológicos aplicados sobre la piel son capaces de permear el estrato córneo, llegar a la granulosa e incorporarse a los cuerpos laminares. Así, la aplicación tópica de lípidos fisiológicos contribuye a restituir la barrera epidérmica no solo por la oclusión, sino también por el aporte del material primario de los nuevos cuerpos laminares.

- Ceramidas: componentes fundamentales de los esfingolípidos, constituidos por esfingosina, que se une al grupo acilo de un ácido graso de cadena larga mediante su grupo amino. Facilitan la diferenciación epidérmica, restableciendo los lípidos celulares.

- Colesterol: esterol de la membrana citoplasmática, precursor de hormonas esteroideas, como las hormonas sexuales y los corticoides suprarrenales, de ácidos biliares y de la vitamina $\mathrm{D}$, que facilita la regeneración y diferenciación epidérmica.

- Ácidos grasos esenciales: que son cada uno de los ácidos monocarboxílicos alifáticos, habitualmente, formados por un número par de átomos de carbono en una cadena hidrocarbonada, casi siempre lineal, saturada o insaturada. Los ácidos linoleico y alfa-linolénico, gamma-linolénico y araquidónico, insaturados y de origen vegetal, son los ácidos grasos esenciales para el ser humano. Tienen actividad antiinflamatoria, inmunógena y antimicrobiana.

\section{Hidratantes ${ }^{7}$}

Las sustancias que mejoran el factor hidratante natural, bien con un papel activo en el mantenimiento del equilibrio acuoso (hidratantes), bien con un papel pasivo (humectantes y oclusivos), equilibran el contenido de agua para restablecer la función de barrera del estrato córneo. Los humectantes pueden extraer agua de la epider- 
mis y dermis, pero también pueden tomarla del ambiente si la humedad es mayor del $80 \%$.

\section{- Humectantes:}

- Glicerol (glicerina): alcohol soluble en agua y etanol, que participa en la estructura de algunas grasas y aceites, como los triglicéridos, y es un intermediario del metabolismo de los ácidos grasos y los hidratos de carbono, que puede actuar como aceptador de fosfato. Se considera el elemento de referencia en hidratación. Tiene un papel primordial corrigiendo el descenso de la acuaporina-3, un transportador epidérmico de agua/glicerol, que conduce a una pérdida de la hidratación ${ }^{17}$. Contribuye al proceso de descamación mediante su capacidad de potenciar la digestión de desmosomas.

- Sorbitol: polialcohol que se obtiene mediante reducción de la glucosa.

- Propilenglicol (propano-1,2-diol): se obtiene por hidratación del óxido de propileno. Se utiliza como disolvente y vehículo, y para aumentar la penetración de determinadas moléculas.

- Urea: componente del factor de hidratación natural. Tiene una gran capacidad de unión al agua, que determina, en gran medida, el balance de humedad de la piel. Su concentración en la piel seca está reducida un $50 \%$ con respecto a la piel sana. Mediante su efecto de rotura de puentes de hidrógeno puede exponer los sitios de unión al agua de la queratina, permitiendo el transporte de moléculas al estrato córneo, lo que provoca un efecto plastificante. Por encima del $10 \%$, tiene efectos proteolíticos y queratolíticos.

- Lactato sódico: compuesto del ácido láctico con sodio con propiedades humectantes. Se ha documentado que promueve un aumento en la síntesis de ceramidas.

- Ácido hialurónico: glucosaminoglucano constituido por una cadena, formada por unidades elementales repetitivas de los disacáridos ácido glucurónico y $\mathrm{N}$-acetilglucosamina, que se pliega para crear una malla más o menos tupida según el grado de polimerización del polisacárido. Se caracteriza por su capacidad para retener agua debido a las cargas negativas y grupos $\mathrm{OH}$ que posee la molécula.

- Oclusivos:

- Vaselina: sustancia mineral semisólida obtenida por destilación del petróleo o por síntesis; sólida, amarillenta o blanca, y untuosa, es una mezcla de parafinas de cadena lineal ramificada y de tipo cíclico. De efecto lubricante, protector de la piel y emoliente.

- Silicona: compuesto humectante organosilícico polimérico, con estructura de siloxano, con radicales orgánicos unidos a los átomos de silicio. Dependiendo del grado de polimerización, se obtienen siliconas de masa molecular y propiedades diferentes. Permiten una formulación sin grasa y tienen un tacto «seco».

\section{Promotores de la diferenciación epidérmica}

- Dexpantenol: precursor del ácido pantoténico, elemento constitutivo de la coenzima A2. El dexpantenol se ha utilizado desde hace tiempo para potenciar la función de barrera de la piel en distintas situaciones, como en la regeneración tras la extracción de injertos cutáneos o tras la irradiación con rayos $\mathrm{X}^{18}$.

- Nacinamida (nicotinamida): amida del ácido nicotínico, vitamina del complejo B hidrosoluble, que actúa como precursora del dinucleótido de nicotinamida y adenina (NAD) y de su fosfato (NADP), coenzimas esenciales para las reacciones redox del metabolismo energético celular. Estimula la síntesis lipídica y la diferenciación queratinocitaria en preparaciones tópicas junto a glicerol ${ }^{19}$.

\section{Fotoprotección}

El daño que la radiación ultravioleta (UV) produce en la piel depende de su capacidad de penetración. La radiación ultravioleta B (UVB) incide 
en las primeras capas de la dermis y origina enrojecimiento y quemaduras. La piel reacciona a las quemaduras solares con mecanismos de acción rápida (inmunidad innata), que preceden al desarrollo de la inmunidad adquirida. Algunos de estos mecanismos (inflamación) acentúan los efectos de la radiación UV y amplifican el efecto lesivo directo en las células, incluyendo el ADN, proteínas y lípidos, lo que causa mayor fotoenvejecimiento. La radiación ultravioleta A (UVA) afecta a las capas más profundas y puede provocar fotoenvejecimiento prematuro de la piel y alteraciones en el ADN. La radiación infrarroja A (IRA) se suma a los efectos de la radiación UV, potenciando su actividad oxidante ${ }^{10}$.

La fotoprotección natural recomienda evitar el sol entre las 11 y las 15 horas solares y llevar una vestimenta adecuada, tejido de trama tupida, no elástico, preferiblemente, de algodón, de color oscuro y acompañado de un sombrero con ala.

La fotoprotección farmacológica está representada por los filtros solares o fotoprotectores tópicos con acción preventiva del fotoenvejecimiento y la fotocarcinogénesis, así como en los casos de fotosensibilidad patológica ${ }^{20}$.

Según su composición, los fotoprotectores tópicos pueden ser físicos, químicos y mixtos. Los fotoprotectores físicos son partículas micronizadas de óxido de cinc, dióxido de titanio, óxido de hierro, óxido de magnesio, silicatos (arcillas, caolín y bentonita) o talco que reflejan la luz. Son inertes, insolubles y presentan gran resistencia al agua. No producen alergias ni fotosensibilidad y no están limitados legislativamente. Los fotoprotectores químicos son sustancias químicas con estructura aromática compuestas por un grupo carbonilo y un grupo donante de electrones (grupo cromóforo), que absorben la energía de los fotones de luz de longitudes de onda determinadas, impidiendo la transmisión de la radiación. Están sometidos a una reglamentación europea, que fija la lista de sustancias autorizadas. Los fotoprotectores mixtos se obtienen al mezclar filtros químicos con físicos que dispersan y reflejan la radia- ción solar. Deben aplicarse todos los días, eligiendo un factor de protección solar (FPS) 30 o superior, que filtren las radiaciones A y B. El FPS es el cociente entre la mínima energía necesaria para producir un eritema detectable con factor de protección y la energía requerida para producir un eritema sin el FPS. Los efectos de la radiación solar están presentes los 365 días del año, incluso en invierno, cuando hay menos luz solar o está nublado, por lo que es necesario protegerse siempre ${ }^{21}$.

\section{Corrección}

Con los cuidados referidos, la piel puede mantenerse en óptimas condiciones en la ancianidad. Pero también se puede desear corregir algunos de los efectos del paso del tiempo, mejorando las arrugas o las alteraciones pigmentarias con diferentes cuidados tópicos correctores, como, por ejemplo, vitaminas, antioxidantes y reguladores celulares tales como factores de crecimiento y péptidos (transportadores, neurotransmisores, señales y otras moléculas antienvejecimiento) ${ }^{10}$.

\section{CUIDADOS DE LAS UÑAS DEL ANCIANO}

Las uñas del anciano requieren unos cuidados periódicos apropiados difíciles de realizar por él mismo, debido al aumento del grosor de las uñas, la dificultad del acceso a los pies, la escasa visión $y$, a veces, la falta de motivación para el cuidado personal. La higiene como en el resto del tegumento, el secado meticuloso en todos los pliegues, y el cortado de uñas sin lesionar la piel son la base.

En cuanto a la onicomicosis, requiere una duración - cercana al año-y una correcta adherencia prolongadas ${ }^{22}$. Teniendo en cuenta este dato, las múltiples interacciones medicamentosas y los efectos secundarios asociados al uso de terapias sistémicas, la terapia antifúngica tópica (como el barniz de ciclopirox en una base hidrosoluble que facilite la penetración ungueal) es de elección en las personas mayores. En los casos de afectación extensa, y teniendo en cuenta las comor- 
bilidades e interacciones medicamentosas, se puede utilizar itraconazol, terbinafina y fluconazol durante cortos períodos de tiempo o como terapia intermitente ${ }^{23}$. Una buena forma de favorecer el acortamiento y la eficacia del tratamiento en los casos de intensa hiperqueratosis es aplicar urea al $40 \%$ en cura oclusiva 5 días antes de iniciar la terapia, limpiar con alcohol de $70^{\circ}$, y eliminar mecánicamente con limas la queratina reblandecida. Este protocolo se puede repetir periódicamente en función de la respuesta.

\section{BIBLIOGRAFÍA}

1. Guerra Tapia A. Cuestión de actitud. Guía práctica sobre el envejecimiento. Barcelona: Ed. Random House Mondadori, S.A.; 2005. p. 5-12.

2. Wong JW, Guerra Tapia A, Koo JYM. Introducing «dermatogeriatrics»: the need for geriatric dermatology as a subspecialty. Más Dermatol. 2012;16:2-3.

3. Rodríguez Peralto JL, Alonso S. Estructura de la piel. En: Iglesias L, Guerra Tapia A, Ortiz P (eds.). Tratado de dermatología. Madrid: Editorial McGraw-Hill Interamericana de España, S.A.U.; 2004. p. 1-11.

4. McGrath JA. Profilaggrin, dry skin, and atopic dermatitis risk: size matters. J Invest Dermatol. 2012;132(1):10-1.

5. Katagiri C, Sato J, Nomura J, Denda M. Changes in environmental humidity affect the water-holding property of the stratum corneum and its free amino acid content, and the expression of the filaggrin in the epidermis of hairless mice. J Dermatol Sci. 2003;31(1):29-35.

6. Barco D, Giménez-Arnau A. Xerosis: una disfunción de la barrera epidérmica. Actas Dermosifiliogr. 2008;99:671-82.

7. Rivera Díaz R, Guerra Tapia A. Tratamientos hidratantes. Dermatol Pract. 2003;4:25-30.

8. Guenther L, Lynde CW, Andriessen A, Barankin B, Goldstein E, Skotnicki SP, et al. Pathway to dry skin prevention and treatment. J Cutan Med Surg. 2012;16(1):23-31.

9. Pérez-Suárez B, Guerra-Tapia A. Características sociodemo- gráficas del cáncer cutáneo en España. Actas Dermosifiliogr. 2008;99(2):119-26.

10. Guerra Tapia A, González-Guerra E. Manual dermocosmético. El rostro. (eBook). Madrid: Editorial Médica Panamericana; 2014. p. 25-9.

11. Guerra Tapia A. Convivir con problemas capilares. Madrid: Editorial Médica Panamericana; 2011.

12. Escalas Taberner J, González Guerra E, Guerra Tapia A. La piel sensible: un síndrome complejo. Actas Dermosifiliogr. 2011;102(8):563-71.

13. González Guerra E. Cambios y trastornos de las uñas en las personas mayores. Act Dermatol. 2006;12:806-14.

14. Guerra Tapia A. Cómo elegir el mejor tratamiento emoliente de la piel seca. Piel. 2013;28(9):552-6.

15. Guerra Tapia A, García del Cañizo C, González Guerra E. Cosméticos y cosmecéuticos: definición, formulación y evaluación de la eficacia y seguridad. Monogr Dermatol. 2012; 25:5-10.

16. González Guerra E, Guerra Tapia A. Aplicación de los cosmecéuticos a la práctica dermatológica. Monogr Dermatol. 2012;25:63-7.

17. Nakagawa $N$. The effect of natural moisturizing factors on the interaction between water molecules and keratin. En: Lodén M, Maibach $\mathrm{HI}$ (eds.). Treatment of dry skin syndrome. Berlín-Heidelberg: Springer-Verlag; 2012. p. 431-9.

18. Rawlings AV, Matts PJ, Anderson CD, Robertts MS. Skin biology, xerosis, barrier repair and measurement. Drugs Discov Today Dis Mech. 2008;5(2):127-36.

19. Alander JT. Chemical and physical properties of emollients. En: Lodén M, Maibach HI (eds.). Treatment of dry skin syndrome. Berlín-Heidelberg: Springer-Verlag; 2012. p. 399-417.

20. González Guerra E, Guerra Tapia A. Fotoprotección. En: Castelo Branco C, Guerra Tapia A (eds.). Envejecimiento de la piel y las mucosas. Madrid: Editorial Médica Panamericana; 2010. p. 105-12.

21. Guerra Tapia A. Mirando al sol o cuando la fotoprotección no existía. Más Dermatol. 2013;21:31-3.

22. González Guerra E, Guerra Tapia A. Dermatosis causadas por hongos. En: Manual y atlas de las enfermedades cutáneas del pie. Barcelona: Editorial Glosa; 2015. p. 94-106.

23. González Guerra E, Guerra Tapia A. Algoritmos terapéuticos en dermatología básica. Madrid: Editorial Médica Panamericana; 2013. p. 43-56. 